\title{
DESIGN OF ACADEMIC INFORMATION SYSTEM BASED ON BOT TELEGRAM IN SMART CAMPUS CONCEPT
}

\author{
Ahmadi, Dedi Setiawan, Suprayitno, Priyadi Hartoko \\ Indonesian Naval Technology College, STTAL \\ Bumimoro-Moro Krembangan, Surabaya, 60178, Indonesia
}

\begin{abstract}
The goal for many education institutions is the existence of the Smart Campus concept. Smart Campus is the concept of a smart campus to provide maximum service to the entire academic community by monitoring and managing existing resources effectively and efficiently. Smart Campus can also provide appropriate information to students or campus institutions in every activity, or even in unexpected events. In this research, it is proposed to maximize the academic information system which is integrated with the Telegram messenger application. This Telegram application can be obtained for free, lightweight and multiplatform by having a fairly complete and more developed Bot API. Students get real time notifications and can chat / communicate with the Telegram Bot which is designed to provide all the information on STTAL. The admin can upload lecture material into the Telegram Bot then students can download it from the Telegram Bot. There are 11 commands designed in this study as a prototype. This research was tested by trying all the commands provided. This Bot Telegram application is very helpful for study program staff and lecturers to convey information to students especially using this application is quite easy.
\end{abstract}

Keywords: Smart Campus, Bot Telegram, and Information Media

\section{INTRODUCTION}

\subsection{Background}

The development of Smart Campus cannot be separated from the rapid development of Information Technology (IT). This technology is used for the convenience of all human activities in all fields. The Smart Campus concept does not only focus on IT infrastructure. The roles of humans, education, social and environment also play a part in realizing Smart Campus. Each school institution has divisions that provide services to the academic community regarding campus affairs. Lecturers or teaching staff, for example, will always deal with academics regarding teaching schedules, materials, meetings and others. Lecturers are also obliged to carry out research and community service, so they will deal with the research and community service sections.

With the current rapid development of technology, it is possible to create an academic information system that is integrated with the telegram application, considering that the use of the telegram application has been widely used in STTAL educational environments. By using a bot to distribute information to students. The use of a telegram bot is needed to provide notifications to the Android application with new information sent from lecturers and study program staff, so that students can get real-time notifications. I chose Telegram application because this application is free, lightweight and multiplatform. Telegram also has a fairly complete and growing Bot API, making it possible to create smart bots that can respond to messages from users.

To follow up on this problem, the author wishes to raise this problem into a final project entitled " DESIGN OF ACADEMIC INFORMATION SYSTEM BASED ON BOT TELEGRAM IN SMART CAMPUS CONCEPT " With this Telegram Bot, it is expected to be able to provide all lecture information in the STTAL environment to students appropriately and quickly.

\subsection{Problem Formulation}

Based on the above problems, it can be formulated how to design and build the academic information system can be formulated as follows:

a. All information cannot quickly be delivered to students, both lecture information and general information.

b. How do you create an academic information system that is integrated into the Telegram application by using a bot? 


\subsection{Research Objectives}

The purposes of Bot Telegram academic information system design are:

a. . Creating an academic information system that implements a Bot telegram. b. Can be used as one of the facilities at STTAL in the Smart Campus concept. c. This system can help optimize the delivery of all information about lectures and general information to students in the STTAL environment in real time.

\subsection{Research Benefits}

The benefits of Bot Telegram academic information system design are as follows:

a. To create an information system with a Smart Campus concept.

b. Optimizing the delivery of all information about lectures and general information to students in the STTAL environment in real time.

\section{LITERATURE REVIEW}

\subsection{Bot Telegram}

As the Telegram Messenger application began to be installed by many people and used for daily conversations, Telegram was not as popular as Whatsapp, BBM, or Line. However, it could be that someday it will become a potential messenger to gain hearts among the virtual community. The advantage of this Telegram is that there is a basis for using the Application Programming Interface (API) for the wider community. One of the APIs provided is a bot feature. Telegram bots are bots that are currently gaining popularity.

Telegram Bot Application Programing Interface (API) is an open source technology provided by Telegram to build Telegram bot applications for developers. This Bot API is an HTTP-based interface for connecting bots developed by developers with the Telegram system (Telegram Bot API, http://core.telegram.org/bots/api.)

Telegram bots are robots in the Telegram application messaging service that can be designed in such a way as we think so that they can function to help automate human tasks. The Telegram bot is a special account that doesn't require a phone number. This account functions as an interface for running code that has been built. For data security, an intermediary server on Telegram will handle all encryption and communication with the Bot API. So that developers don't need to know how the MTProto encryption protocol on the Telegram server works.

\subsection{Bot Telegram}

Bot telegram is really very helpful as shortcuts and assistants to carry out their functions quickly and precisely. In simple terms, how the telegram bot works can be illustrated in figure 2.1:

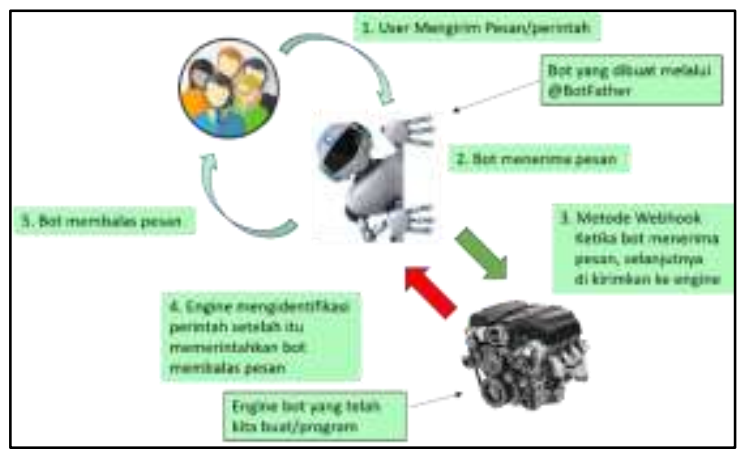

Figure 2.1 Bot Description follow :

The explanation of figure 2.1 are as 


\section{a. User sends message}

In this case the user is a student, must first send a message to the bot. Usually begins with / start which means the user has allowed himself to receive messages from the bot. Not allowed by telegraph if the bot sent the message first. This is to prevent spaming cases.

\section{b. Bot Receiving Message}

The bot will receive a message. When receiving a message, the bot treatment is what we ordered. By default the bot will save incoming messages until we retrieve them.

\section{c. Retrieving Messages}

The bot / engine program must actively request messages, this method is known as polling. Another method is webhooks. Where we will setup the bot so that the bot process when it receives a message, the bot will immediately send it to the web (engine) we want.

\section{d. Order the Bot to Reply to the Message}

After the message is received, the message is processed whether it is ignored or replied to. If you want something in return, what about it. So here is the role of the engine that we create, process the message, process it, then prepare the answer. After the answer is there, then we instruct the bot to reply to the message according to the definition we have programmed.

\section{e. Bot Reply to Message}

The bot receives the message then continues sending replies / responses to the user.

\section{RESEARCH METHOD}

\subsection{Research Design}

In this design research, the author will describe the system design that will be carried out in stages according to the required needs. It will be based on the process of delivering information as the main subject of the system design entitled Academic Information System Design Using Telegram Bot.

\subsection{Research Procedure}

The research procedure is a series of activities carried out by researchers periodically and systematically to pursue research objectives in order to better understand how to conduct research and the problems faced as a basis for designing a system that is planned according to the sequence of events. The research procedure for the design of an academic information system using a telegram bot in the smart campus concept can be seen in Figure 3.1.

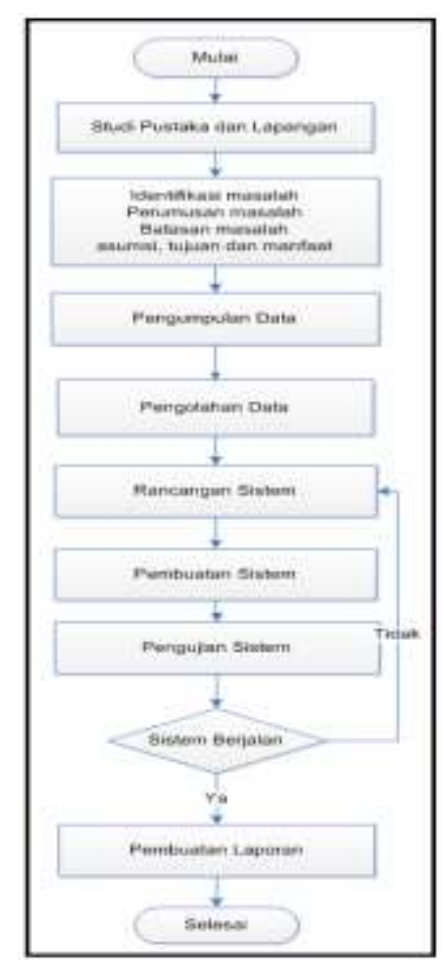

Figure 3.1 Research Procedure

\subsection{Research location and time}

The research location is a place or area where the research will be carried out. The research conducted by the author took place at the STTAL Moro Krembangan Campus in Surabaya. The time used in this study was from July 2019 to the end of December 2019.

\subsection{Tools and Materials}

In carrying out this research, several tools and materials are needed to facilitate the design and research trials. The tools and materials needed in conducting research include:

a. Personal Computer (PC) / Laptop.

b. Mobile (HP).

c. Firebase Database, used as a database management system processor.

d. PHP, is a server-side scripting language that integrates with HTML to create dynamic Web pages.

e. Domain, is a unique name given to identify the address (IP address) of a 
computer server such as a web server or email server on the internet.

f. Hosting, is a rental place to accommodate the data needed by a website so that it can be accessed via the internet.

g. Bootstrap, is a framework for good performance.

h. Macromedia Dreamweaver. Professional HTML editor for designing and managing websites and web pages visually.

i. XAMPP

\subsection{Research Design}

The design of an overview of the research is the stage of studying the existing system based on the results of an analysis of existing problems. Then various analysis data are reviewed to get an overview of the system as a whole. The system overview presents each part of the system and the relationships between the parts related. Figure 3.2 below is an overview of the Telegram Bot-Based Academic Information System.

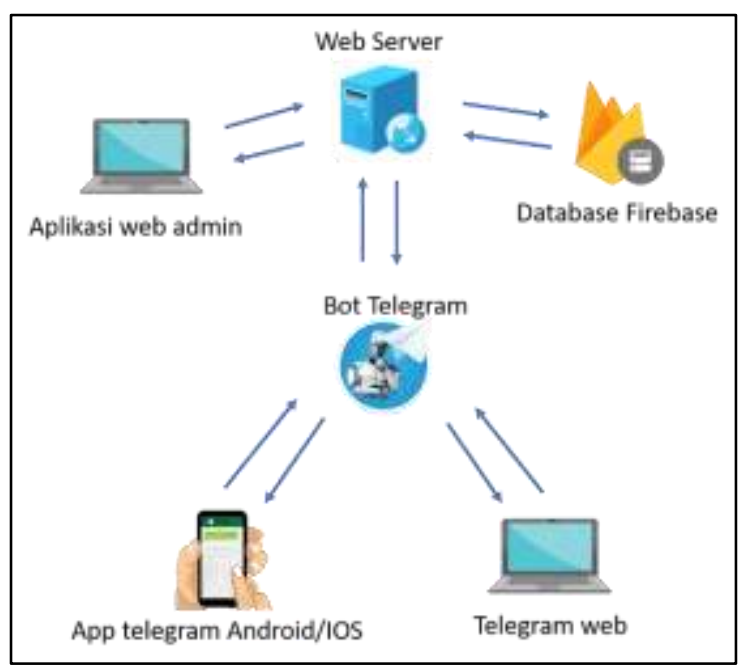

Figure 3.2 General Description

From the general description of the design of the Telegram Bot-Based Academic Information System in Figure 3.2 above, it can be explained as follows:

a. Web server, is an application that provides HTTP and HTTPS request services that can be run on a web browser. The application that runs on a web server consists of two general parts, namely, the telegram bot system and the web admin. The telegram bot system on the web server is tasked with serving data requests from the telegram application and the web admin is a data processing web server for academic information systems. b. Telegram and web telegram applications, are telegram applications that run on the Android / IOS platform and web browser.

c. Firebase database, functions to store data accessed via the web admin.

d. The admin web application is a device for accessing the web admin, usually done using the Mozilla browser, Chrome and others.

e. Telegram bot, is a robotic application to carry out commands that can be executed by web applications to serve user requests.

\subsection{System Design}

According to (John Burch and Garry Grudnitski, 1986), "a system design can be defined as a drawing and a sketch or an arrangement of separate elements into one, all functioning together." From this definition, it can be concluded that the system design is the stage of drawing, planning and manufacturing to unite several separate elements in a single system to clarify the system.

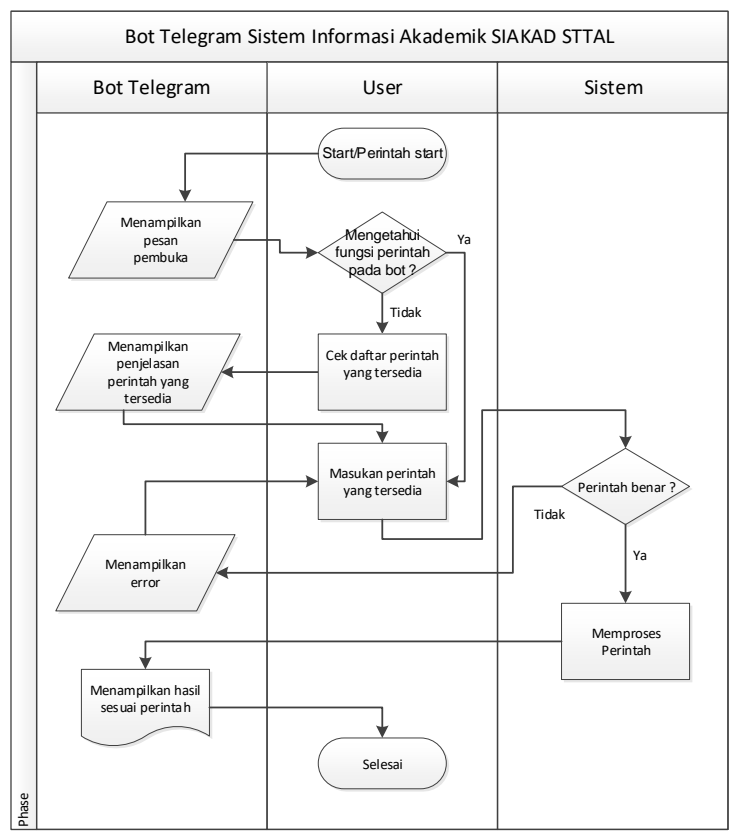

Figure 3.3 Diagram flow of data information process

Figure 3.4 is a Flow Diagram of STTAL Academic Information Process using a telegram bot. In this process after the user / client adds the Telegram SIAKAD STTAL bot as a friend, first the user / client must start a 
conversation by entering the command / start command. Then the bot will display a welcome message. If the user does not know the commands contained in the bot, then the user can enter the command / help to display the commands on the bot and their explanations. However, if the user already knows the command functions in the bot, the user can immediately enter the desired command. After that the system will check whether the command entered is correct or not. If the command is entered incorrectly, the bot will display an error message to the user and the user will re-enter the correct command, the system will process the input then the bot will display the results according to the command input, and the user can re-enter the command or end the conversation with Bot.

\subsection{Command Bot Telegram Design}

In designing a command or command on a telegram bot, the author determines the command or command, as follows:

a. I Start: Command to enter Siakad system.

b. / KHS: to find out the student's KHS per semester.

c. / Lecturer: to find out the schedule of the teaching lecturer per semester.

d. / Schedulepel: to find out the schedule of lessons that will be held.

e. / Exam schedule: to find out the exam schedule, uts and uas.

f. / Kalakademik: to find out the academic calendar in two semesters.

g. / E-learning: to find information or tutorials on the use of the telegram bot application, tutorials and knowledge of subject subjects.

h. / Information: to find general information on STTAL.

i. / help: to find a list of commands used in the telegram bot application.

j. / KebPDK: to obtain data or documents needed by PDK for the smooth running of lectures.

k. / Stop: Command to stop or exit the Siakad system.

\subsection{Makin Bot Telegram Account}

Initially, it is necessary to create a suitable Bot account to get the name and API of the Bot account. The request for creation is made through the Botfather account on Telegram Messenger, this account is an official Bot account from Telegram which is the main Bot that will manage all the bots that are made. To find it, use the search field and type @Botfather.

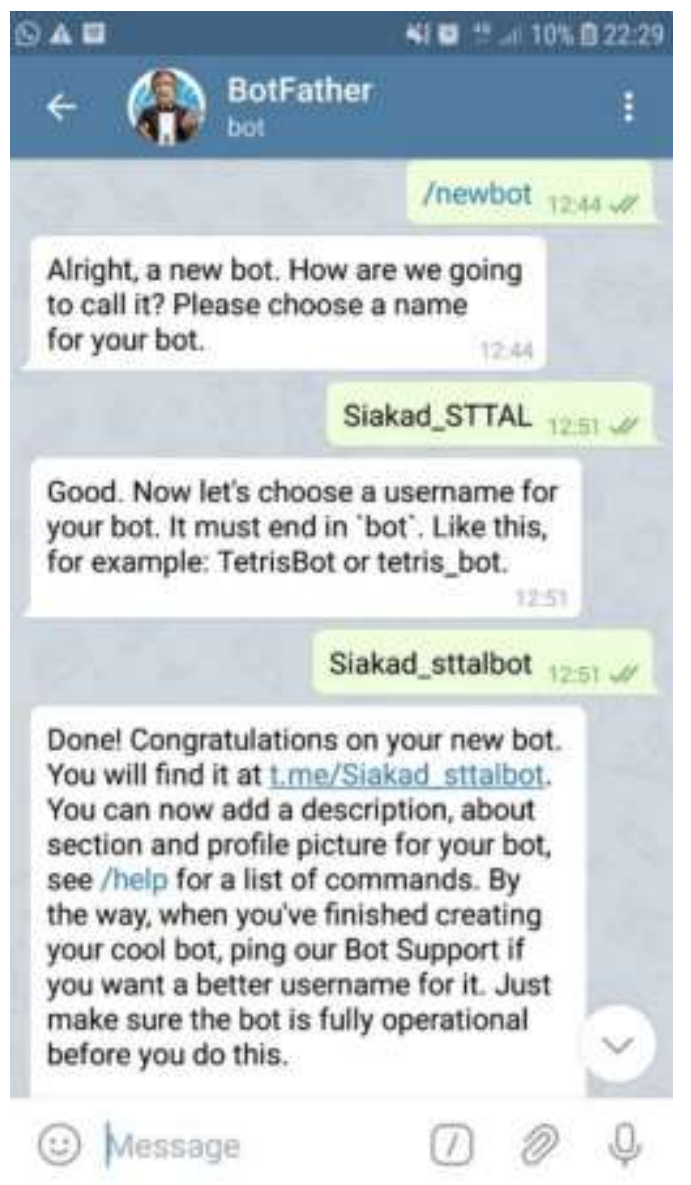

Figure 3.4 Making Bot Telegram Account

\section{ANALYSIS AND DISCUSSION}

\subsection{SIAKAD Design Analysis and Design with Bot Telegram}

In designing a Telegram Bot-Based Academic Information System, it is necessary to first analyse the system requirements. The need to fulfill the formation of an Academic Information System Based on Telegram Bot can be described as follows:

a. Telegram bot, is a robot application that can be programmed with various kinds of commands or commands to run a series of instructions that the user needs. This series of instructions constitutes academic information.

b. Boostrap framework, is a work area in the form of css that can be used to build a web application.

c. Firebase, is a database in the form of a cloud server with JSON data format, Firebase real time database is a NOSQL database, which means a database that does not require queries to run data requests. Firebase is in the form of a data tree, so that users can directly 
access the data information contained therein.

d. Telegram is an open source, cloudbased, multiplatform instant messenger service application.

e. Web server, is a program that provides data-based services and functions to receive requests from HTTP or HTTPS on a known client and is usually known as a web browser.

To describe the web admin system, it can be seen in Figure 4.2 which is a block diagram of the web admin system design. In block diagram 4.2 the writer designed web application menus which consisted of the following menus:

a. Login menu, is a menu to enter the web admin system.

b. Logout menu, is a menu to exit the web admin system.

c. Menu rank, admin can manage rank data with the rights to Create, Update and Delete (CRUD).

d. Corps menu, admin can manage corps data with the rights to Create, Update and Delete (CRUD).

e. Student menu, admin can manage student data with the right to Create, Update and Delete (CRUD).

f. Inside the lecturer menu, the admin can manage the lecturer data inside with the right to Create, Update and Delete (CRUD).

g. External lecturer menu, admins can manage external lecturer data with the right to Create, Update and Delete (CRUD).

h. Menu rank, admin can manage rank data with the rights to Create, Update and Delete (CRUD).

i. KHS menu, admin can manage KHS data with the right to Create, Update and Delete (CRUD).

j. In the study program menu, the admin can manage study program data with the right to Create, Update and Delete (CRUD).

k. PDK menu, admin can manage PDK data with the rights to Create, Update and Delete (CRUD).

I. Lesson schedule menu, admin can manage lesson schedule data with the right to Create, Update and Delete (CRUD).

$\mathrm{m}$. In the exam schedule menu, the admin can manage the exam schedule data with the right to Create, Update and Delete (CRUD). n. Data menu for course subjects, the admin can manage course data with the right to Create, Update and Delete (CRUD).

o. Menu of academic calendar data, admins can manage academic calendar data with the right to Create, Update and Delete (CRUD).

p. In the e-learning data menu, the admin can manage e-learning data with the rights to Create, Update and Delete (CRUD).

q. The latest information data menu, the admin can manage the latest information with the right to Delete.

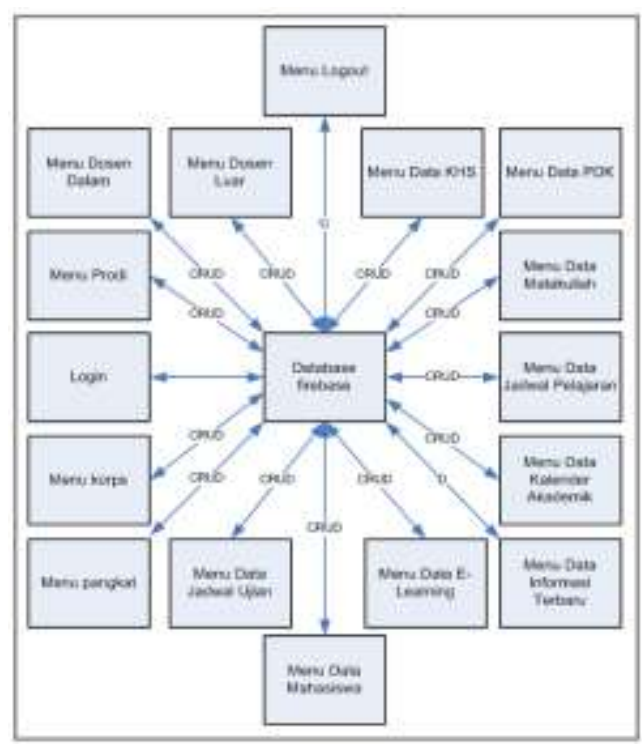

Figure 4.1 Web Admin System Block Diagram

\subsection{System Implementation}

The use of the program can be implemented after all software components that support the academic information system application process with the smart campus concept use a telegram bot. If the use process is carried out properly, the system is expected to be able to run to provide all lecture information in the STTAL environment to students appropriately and quickly.

For the implementation of the Telegram Bot-Based Academic Information System, several things the author needs to do are as follows:

a. Firebase

Added Firebase SDK (Software Development Kit) and Firebase initialization in web applications. Here's the web program code for adding the firebase SDK and initializing it. 
$<$ script

src="https://www.gstatic.com/firebasejs/4.3.1/fi

rebase.js" $></$ script $>$

<script type="text/javascript">

var $\mathrm{KEY}=$ ";

var config $=\{$

apiKey:

"AlzaSyBGSf7H6TVTXFTE7PhEosS0hrOb5U

EmJw0",

authDomain: "bottelegram-

2a741.firebaseapp.com", databaseURL: "https://bottelegram-

2a741.firebaseio.com",

projectld: "bottelegram-2a741", messagingSenderld:

"852992905710", appld:

"1:852992905710:web:17c99dd07b2e0192" \};

firebase.initializeApp(config);

Figure 4.2. Adding SDK (Software Development Kit)

b. Telegram Bot

Adding bot token and bot url link in web application. The following is the web program code for adding the bot url and token.

Var bottoken

="bot967453268:AAExGqq_jJ4Smzpu

Tw01k_V4u5yLUQVnXOA";//"bot83816

7596:AAEe0m0nEcnjkJuYm6iy8PSJZS DL3QnYJv8";

var boturl = "https://api.telegram.org/" + bottoken;

Figure 4.3 Adding Bot Token and Bot url in web aplication

\section{c. Dashboard}

Home Dashboard is the initial menu after entering the website on the information system that has been designed for admin access rights via the link http:

//localhost/telegramadmin/index.php.

The initial dashboard image for the user can be seen in Figure 4.4.

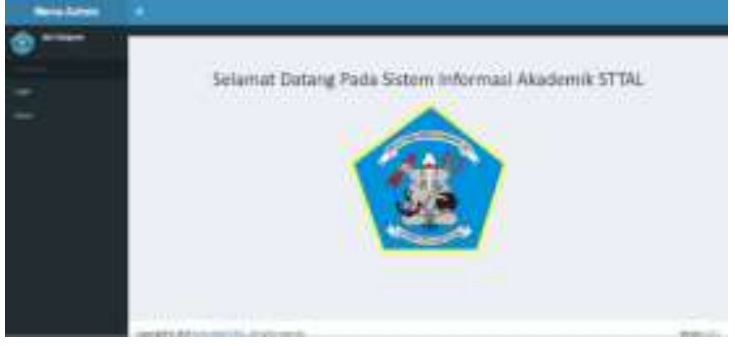

Figure 4.4 Admin Dahsboard

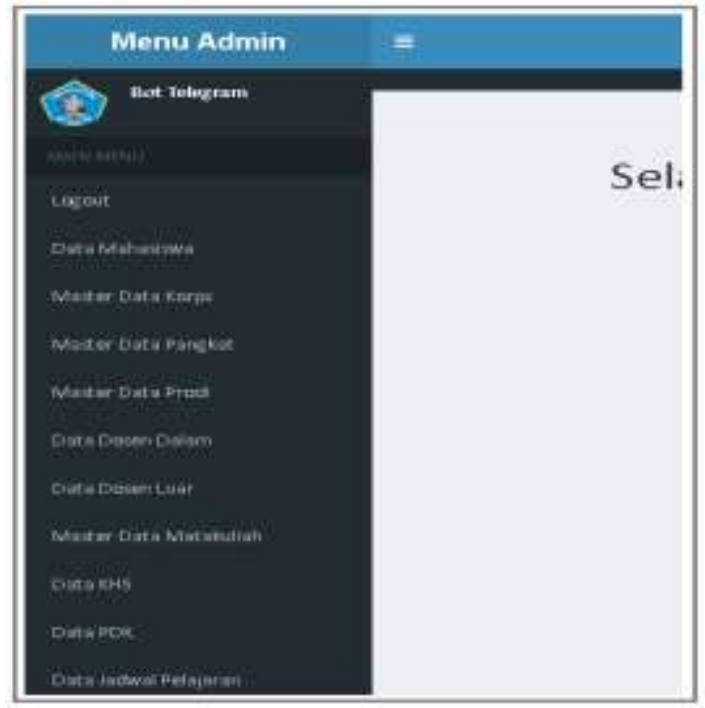

Figure 4.5 Dashboard Menu

\subsection{Bot Telegram testing}

Bot Telegram testing on STTAL student academic information systems is a test of integration of academic information systems with telegram bots. In this test, it is divided into two parts, namely: server.

a. Testing a bot application on a web

b. Testing the telegram application for Android devices.

To run the telegram web bot, it is necessary to run the bot.php page on the server application. To run the bot web server, you can type it in the address bar of the web browser, as in Figure 4.6 below.

a pakdedibot.ooowebhostapp.com/bot.php

Figure 4.6 Run Server Web Bot on Browser. 
After the bot.php page is run, the telegram bot can be accessed in the Telegram application on an Android device. Before you can start talking to bots, you must first add a Telegram bot account by searching for the username @STTAL_bot. At the start of using the Android telegram bot application, the user needs to give the / start command and the telegram bot will reply as shown in Figure 4.7 below.

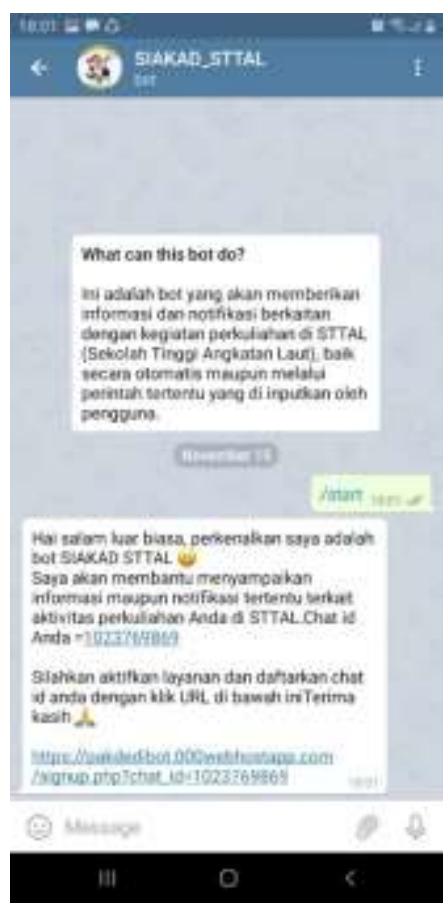

Figure 4.7 Command/start testing

In accordance with the instructions given by the telegram bot, the user must activate the service by registering the chat id on the link provided. The following shows the activation of the telegram bot service which is presented in Figure 4.8 below.

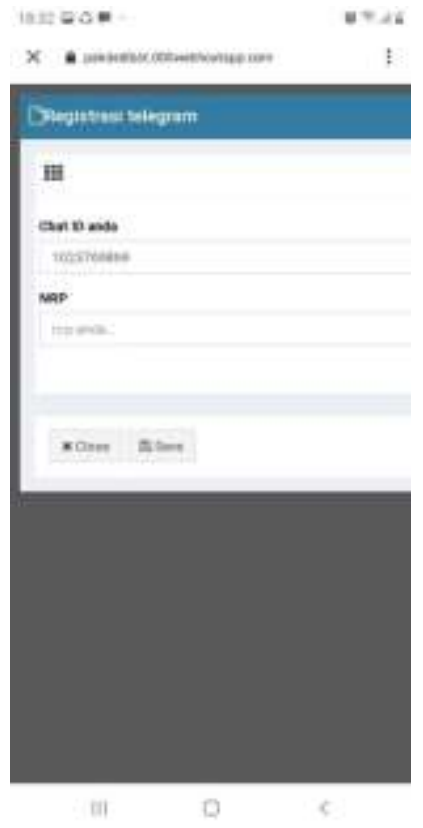

Figure 4.8 Chat ID activation display

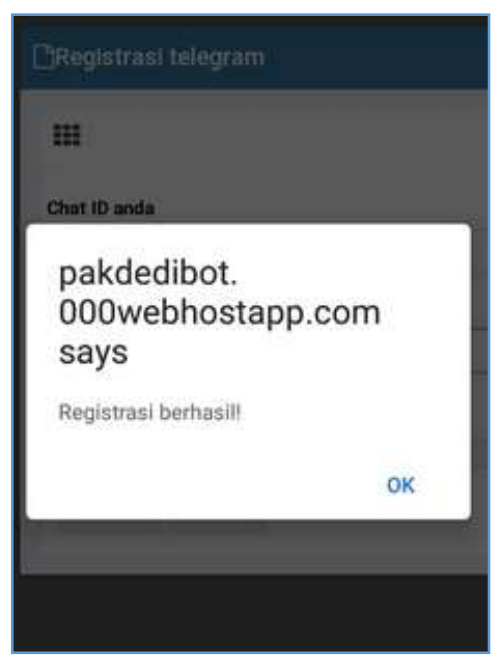

Figure 4.9 Success Activation Notification Display

After the registration and activation process is successful, the user can use the features provided by the telegram bot. To be able to see the features provided, you can use the command / help on the Telegram application. The following is the help display image shown in Figure 4.10 below 


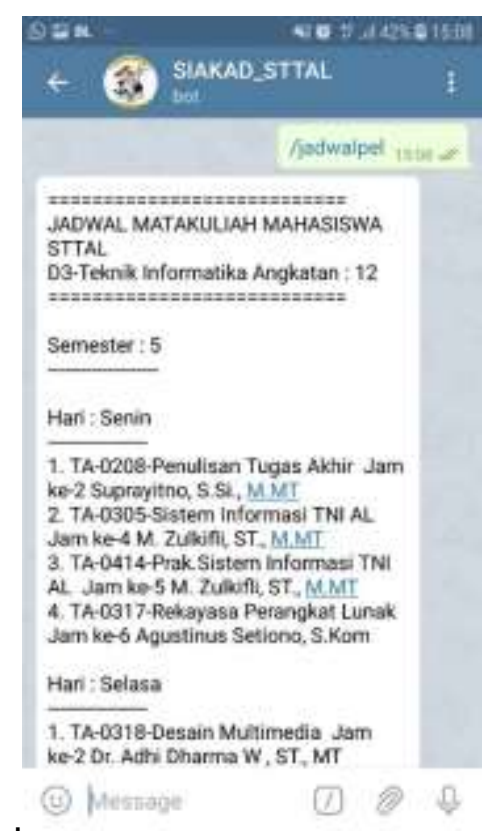

Figure 4.10 Command/jadwalpel Testing

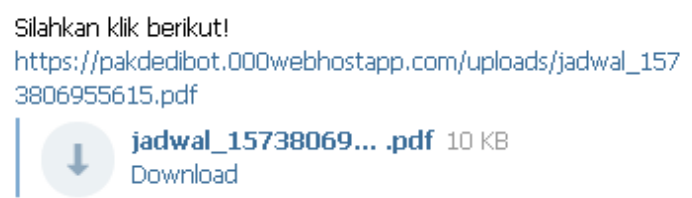

Figure 4.11 Download Link of Lesson Schedule Display

\subsection{Result}

Research on the design of the Academic Information System with the Smart Campus concept at STTAL using the Telegram bot was carried out by testing the whole system. The research results were obtained based on tests carried out on the downloaded files from the Telegram bot reply.

a. The results of downloading the file from the Telegram bot reply using the / khs command which is an excel file, can be seen in Figure 4.12.

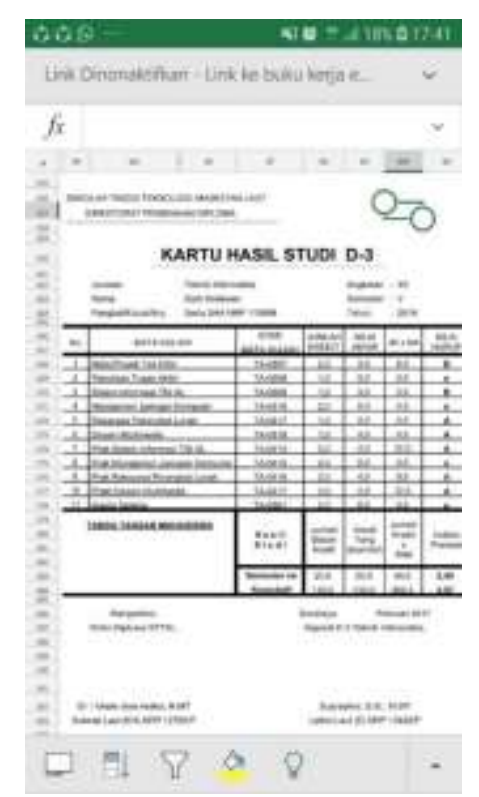

Figure 4.2 File Download Replay of Command /khs Result

b. The results of downloading the file from the bot's reply using the command / schedule an excel file, can be seen in Figure 4.13.

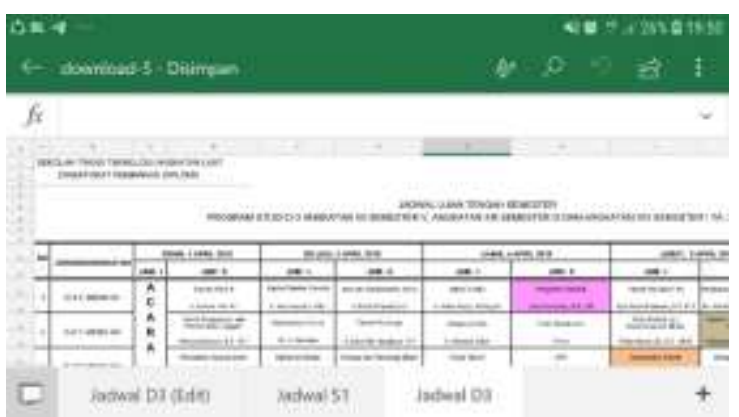

Figure 4.3 File Download Replay of Command /jadwalujian Result

c. The result of downloading the file from the bot's reply using the command / calendar which is an excel file, can be seen in Figure 4.14.

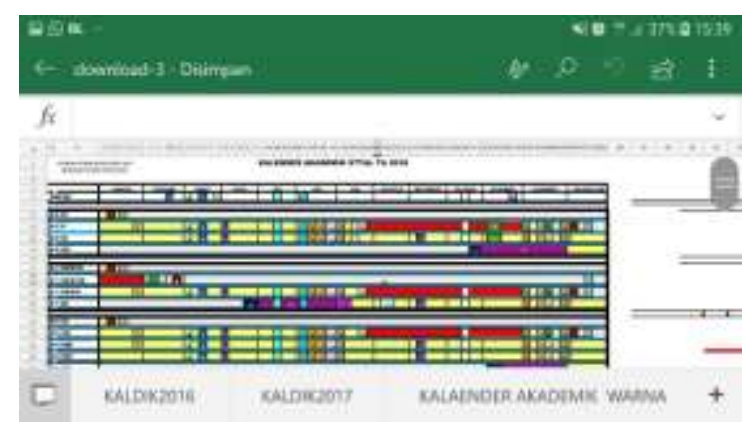

Figure 4.14 Download File Command /kalender Result 
d. The result of downloading the file from the Telegram bot reply using the command / schedulepel which is a pdf file, can be seen in the figure 4.15.

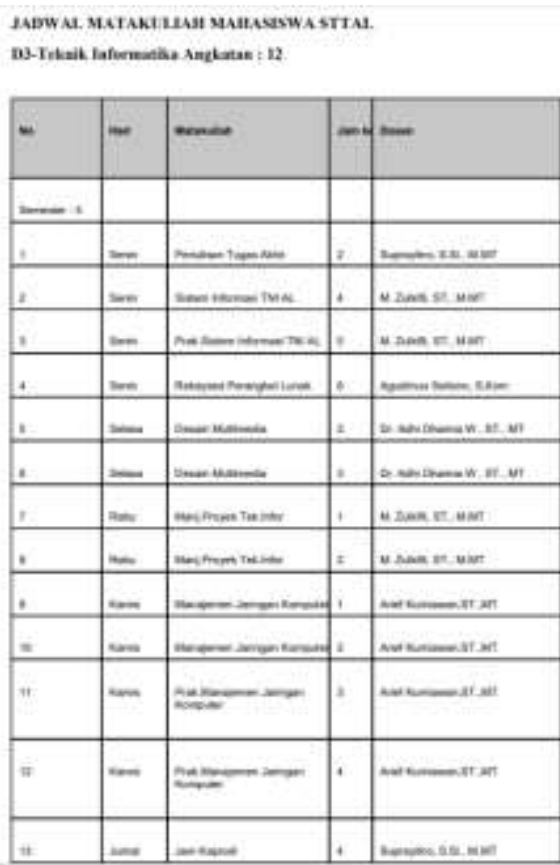

Figure 4.15 Download File Reply Command /jadwalpel Result

\section{CONCLUSIONS AND SUGGESTIONS}

\subsection{Conclusions}

The conclusions on academic information system research with the concept of smart campus using this telegram bot are:

a. The STTAL SIAKAD Telegram bot is to provide information to students has been successfully created.

b. There are 11 commands made in this study as an initial prototype.

c. It is very useful and makes it easy for students to obtain lecture information as well as general information while carrying out lectures at STTAL.

d. This information system is intended for the entire STTAL academic community to be used as one of the facilities at STTAL in the Smart Campus concept.

\subsection{Suggestions}

The design of an academic information system using Telegram Bot still requires development suggestions based on the results of the tests that have been carried out, as follows: a. The design of the command in the Telegram bot should be refined to make it more attractive.

b. Added student value management so that lecturers can input grades from the Telegram bot.

c. The bot server can be connected with sensors installed on campus to find out information on the campus environment, lecturer status, polls and attendance processes.

\section{ACKNOWLEDGEMENT}

The authors greatly acknowledge the support from Naval Technology College, STTAL Surabaya Indonesia for providing the necessary resources to carry out this research work. The authors are also grateful to the anonymous reviewers and journal editorial board for their many insightful comments, which have significantly improved this article.

\section{REFERENCES}

Cokrojoyo, Anggiat. 2017. Pembuatan Bot Telegram untuk Mengambil Informasi dan Jadwal Film Menggunakan PHP.

F. A. Hanif, Analisis \& perancangan system informasi, Penerbit ANDI, Yogyakarta: STMIK AMIKOM, 2007.

Leitch Robert A., K. Roscoe Davis. Analisis \& Desain. Andi. Yogyakarta, 2005.

Putra, C. A 2014. Penjelasan Struktur Data JSON.http://www.candra.web.id/penjelas an-strutur-data-json/ 